$$
\begin{aligned}
& \text { التنمية الزراعية المستدامة في محافظة الحسكة } \\
& \text { (دراسة جغرافية) } \\
& \text { صالح عبد السلام حسين } \\
& \text { قسم الجغرافية، كلية التربية الأساسية، جامعة دهوك، اقليم كردستان ــ العراق } \\
& \text { (تاريخ استلام البحث: } 30 \text { تشرين الاول، 2017، تاريخ القبول بالنشر: } 13 \text { آذار، 2018) }
\end{aligned}
$$

الخلاصة

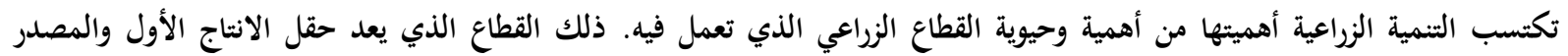

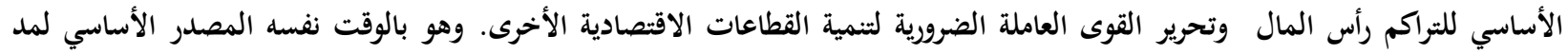

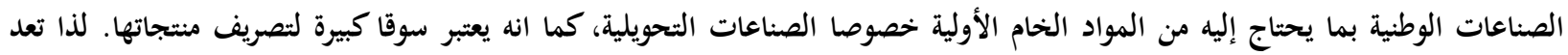
التنمية الزراعية المقدمة الضرورية لتحقيق التنمية الشاملة.

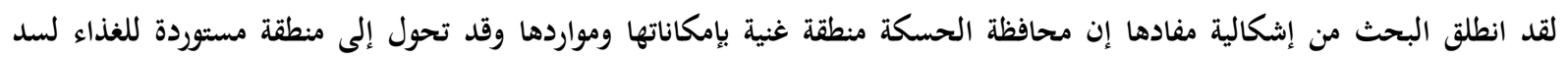

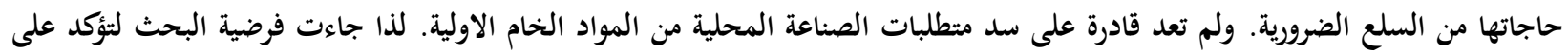
ضرورة تبني المفاهيم المعاصرة للإصلاح الزراعي. وإعادة بناء العلاقات الإنتاجية واستخدام التقنيات المعاصرة لتحقيق التنمية الزراعية المنشودة. بناء على ماتقدم جاءت هيكلية البحث مكونة من ثلاثة مباحث أساسية وهي التنمية الزراعية(مدخل نظري).

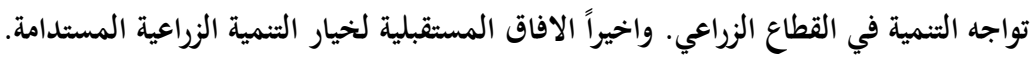

الكلمات الدالة:التمية (Development) التنمية الزراعية (Development Agricultural) التنمية المستدامة (Sustainable) (Sustainable Agricultural Development) الاستدامة(Sustainable) التنمية الزراعية المستدامة Development

وصل بين ثناث دول (سوريا-تركيا-العراق) ، تمدها تركيا المقدمة

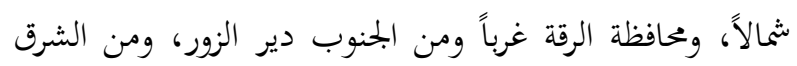

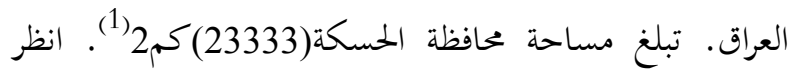
تقع محافظة الحسكة في أقصى الشمال الشرقي من سوريا ، بين دائرتي عرض(36,25 - 37,15)شمالاً، وبين درجتي طول الخارطة رقم(1). (42,18-40,18) شرقاً، تعد موقعاً استراتيجياً مهماً بمثابة منطقة درجن 


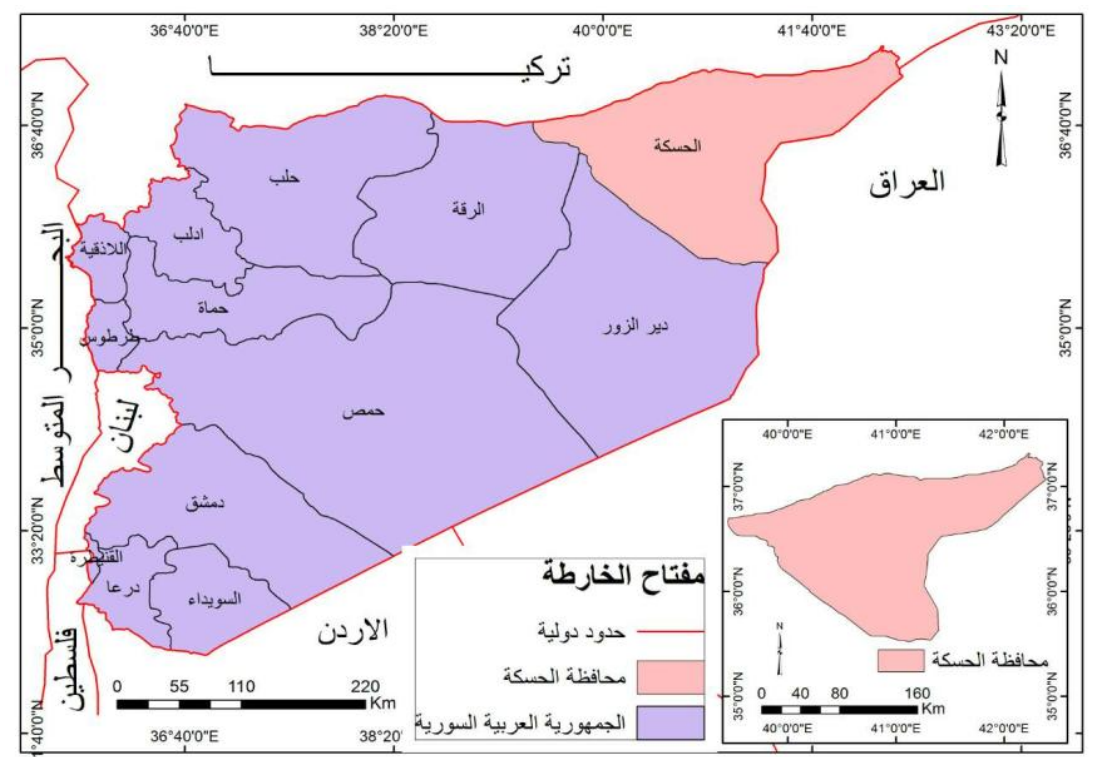

خارطة(1-1): موقع محافظة الحسكة بالنسبة الى سوريا ودول الجوار

المصدر عمل الباحث بالاعتماد على الهيئة العامة للاستشعار عن بعد، دمشق، 2015

أهمية البحث:

تكمن أهمية البحث في تقييم الموارد الطبيعية والبشرية في

محافظة الحسكة على أساس أها أهم مقومات التنمية الزراعية.

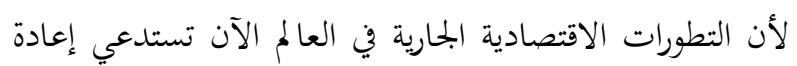
تقييم لكل المراحل السابقة، للوقوف على جوانب القصور في

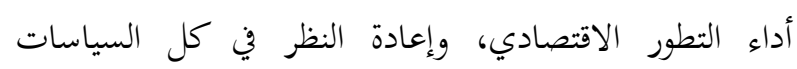
التنموية، وإجراء تقييم شامل لكل الموارد (الطبيعية والبشرية) لتحديد مدى مساهمتها في الاقتصاد الوطني والعمل على تلافي

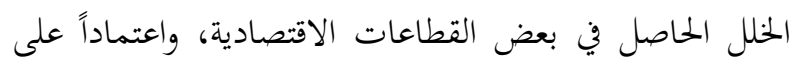

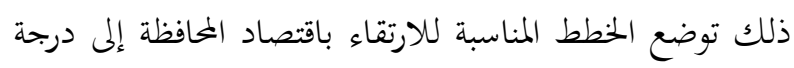

$$
\text { يككنه معها مواجهة هذه التطورات. }
$$$$
\text { أهداف البحث: }
$$

تمدف الدراسة إلى كشف وتحليل مقومات التنمية الزراعية وكيفية توظيفها بالشكل الذي يساعد على تحديد أهم

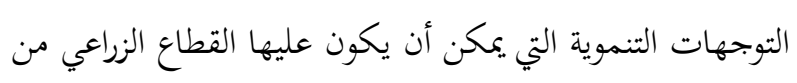
خلال وضع استراتيجيات مناسبة بما يضمن زيادة الرقعة الزراعية

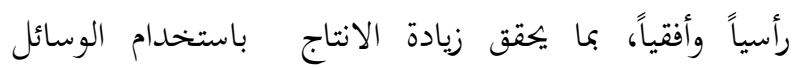

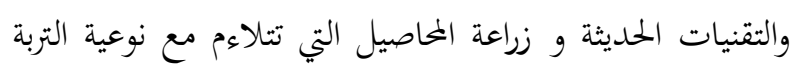
والمناخ.
تعد محافظة الحسكة من المناطق المهمة التي تتصف

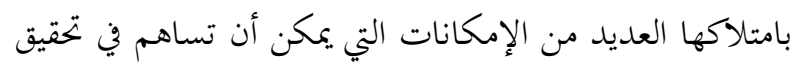
قدر كبير من الإنتاج الزراعي، إذا ما استغلت بالطرق العلمية

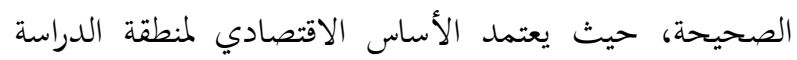
بشكل كبير على القطاع الزراعي، فضلاً عن كوها الظهير الزراعي لسكان محافظات السورية الاخرى، نظراً لسعة المساحة ) الصالحة للزراعة والبالغة

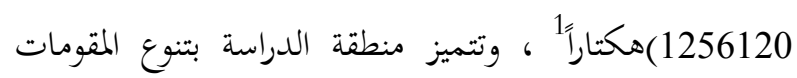

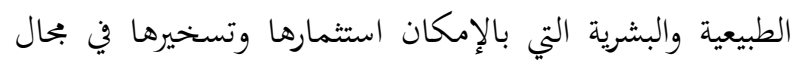

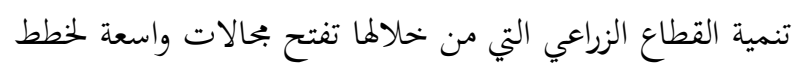
التنمية الاقتصادية. من هنا جاءت هذه الدراسة ( التنمية الزراعية في محافظة الحسكة دراسة جغرافية)، إذ تعد إحدى أهم الوسائل التي يمكن

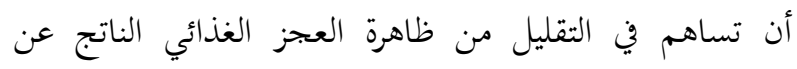
التضخم السكاني، وتركز سياسة التنمية الزراعية على أن تكون

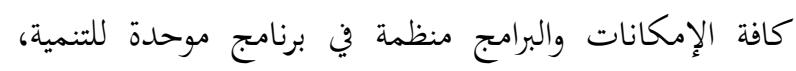
لغرض تنمية القطاع الزراعي وإقامة المؤسسات لخدمة الإنتاج الموجه نحو السوق وتنظيم حيازة الارض وتحسين مستوى الدخل

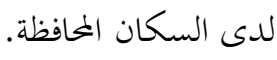




\section{المبحث الأول: التنمية الزراعية (مفاهيم نظرية)}

\section{اولا: التنمية الزراعية المستدامة:}

وهي كافة الإجراءات التي تسهم في تطوير القوى المنتجة

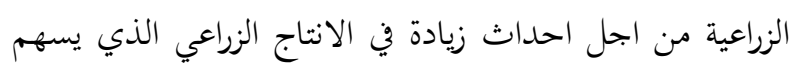
بدوره في عملية التنمية الاقتصادية الزراعية، إذن يكون المفهوم

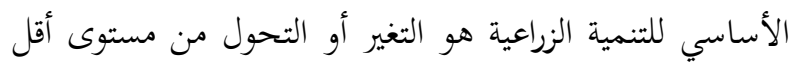
للمردود والانتاجية الى مستوى أعلى، يكون بالمستطاع زيادته من خلال تطبيق برامج وأساليب وتقنيات ملائمة.

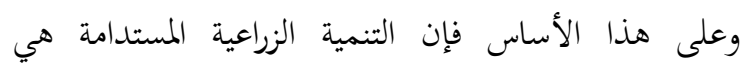

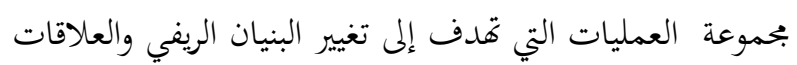

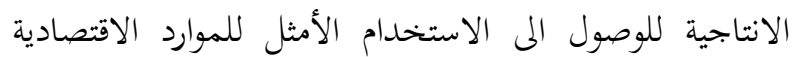
بهدف زيادة الانتاج الزراعي، وزيادة الدخل الحقيقي للفرد والتي تتحقق من خلال السياسات الاقتصادية، كالسياسة الزراعية

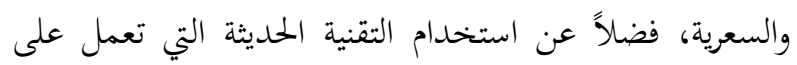

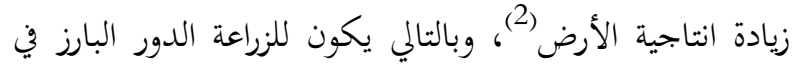
تحقيق التنمية الاقتصادية. وحسب منظور منظمة الأغذية والزراعة التابعة للأمم المتحدة ، فإن التنمية الزراعية المستدامة هي إدارة وصيانة قاعدة

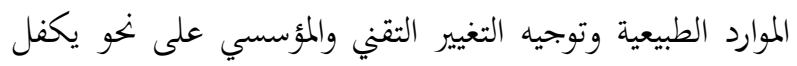
تحقيق الاحتياجات البشرية للأجيال الحاضرة والمقبلة وتلبيتها باستمرار (3).

ثانياً: أهداف التنمية الزراعية المستدامة: إن التنمية الزراعية المستدامة تعتمد على العامل البشري

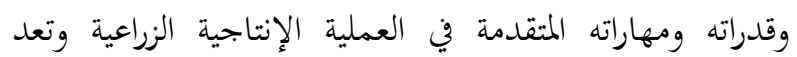
التنمية الريفية الوجه الاخر للتنمية الزراعية، ومن هنا تبرز أهمية

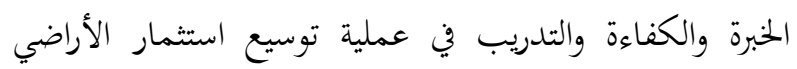
الزراعية وزيادة إنتاجها كما ونوعا مما يؤثر في التنمية الاقتصادية من خلال توفير الاحتياجات الغذائية للسكان وتحقيق الأمن الغذائي وتأمين الاحتياجات المستقبلية للأجيال الراهنة، ويمكن تلخيص تلك الاهداف بمايلي:
مشكلة البحث:

تتحدد مشكلة البحث بوجود مساحات زراعية واسعة صالحة للزراعة، ولكنها غير مستثمرة بطريقة صحيحة، وهي مهملة في جميع مقومات التنمية الزراعية، مما انعكس سلباً على تدهور مستوى الانتاج الزراعي فيها واهمال خطط التنمية التي تستثمر مثل هذه الاراضي الغنية بالموارد الطبيعية. فرضيات البحث: ت ت تفترض الدراسة وجود مساحات واسعة من الاراضي الزراعية في محافظة الحسكة ولم تستثمر بطريقة صحيحة. كما تفترض الدراسة بأن عدم استثمارها بطرق علمية صحيحة يساهم في تدهور انتاجها من المحاصيل الزراعية، مما خلق مشكلة كبيرة انعكست على تدهور المستوى المعيشي وتدهور القطاع الزراعي في المحافظة. مناهج البحث:استخدام المنهج الوصفي التحليلي الذي سيهدف الى جمع الحقائق والبيانات حول الظاهرة الجغرافية ويحاول تفسيرها تفسيراً وتحليلاً علمياً. كما واتبع الباحث الأسلوب التحليلي الإحصائي لمعالجة

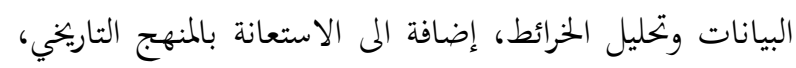
وذلك في تتبع تطور بعض التحولات المناخية والزراعية.

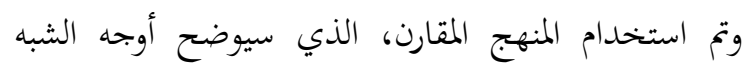
والاختلاف بين المناطق الادارية في المساحات الصالحة للزراعة والمزروع فعلاً على مستوى محافظة الحسكة.

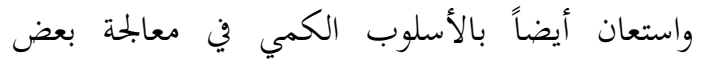
البيانات وحساب المتوسطات الإحصائية ووضع الرسوم البيانية

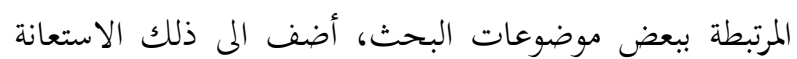

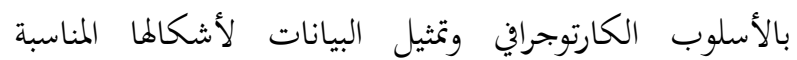
وإسقاطها على خرائط لتسهيل فهمها وتأكيدها، إضافة الى استخدام بعض الصور الفوتوغرافية متنوعة تخص منطقة البحث. 
انعاش القطاع الزرعي سيكون لها الاثر على تنمية القوى البشرية

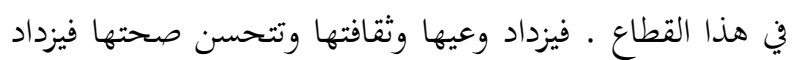
عطائها الانساني، فتتحقق بذلك إرادة التنمية. 4- ت تأمين مثطلبات الصناعات التحويلية الخفيفة. تعد الصناعات التحويلية الاستهلاكية الاساس لتنمية

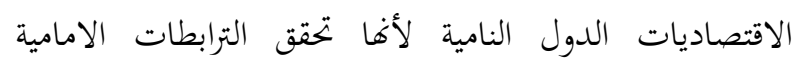

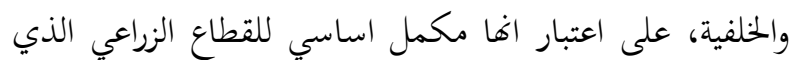
يعد المصدر الرئيسي لإمداد الصناعات التحويلية بما تحتاج إليه

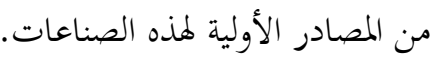
وعلى هذا الاساس لا ينبغي ان نتصور قيام صناعات غذائية محلية ناجحة بدون زراعة واسعة وكثيفة. مثلا فلا صناعات نسيجية متطورة بدون زراعة واسعة للمحاصيل الصناعية. 5- التنمية الزراعية توفر البيئة الصالحة للحياة. يعيش العالم اليوم مشكلة كبيرة بسبب تلوث بيئة الانسان،

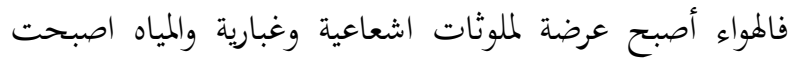
اكثر عرضة للتلوث بفضل اختلاطها بالمياه الثقيلة والنفايات

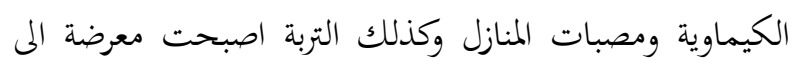
الكثير من الملوثات التي تجعل منها بيئة غير صالحة لحياة الانسان. لذا فان التنمية الزراعية سيكون من أهم وظائفها إصلاح ذلك الخلل في البيئة.

\section{المبحث الثاني: التنمية الزراعية (الواقع والتحديات)}

لبيان واقع القطاع الزراعي وتشخيص التحديات التي تحول

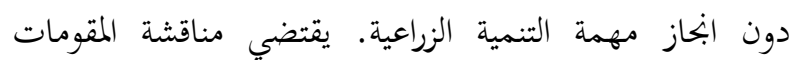
الاقتصادية التي تتحكم بهذا الواقع. وهي:

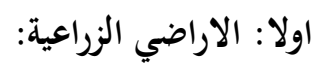

تبلغ مساحة محافظة الحسكة( 23333كم)2. الصالحة للزراعة (1566008هكتار) أي ما نسبته 67.2\% من من ماحسة

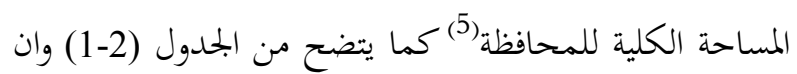
المستثمرة فعليا من تلك الاراضي حوالي (1562345هكتار)
1- ت تأمين احتياجات المواطنين من الغذاء.

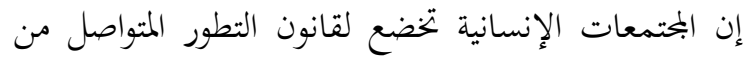
حيث زياد أعدادها ومن حيث تنوع ثقافاتا. الامر الذي يترتب الإنباتيه عليه الازدياد المتواصل في الطلب على السلع الزراعية بشقيها

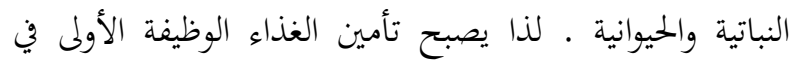

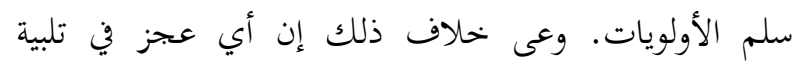

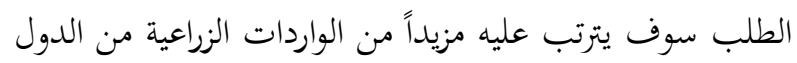

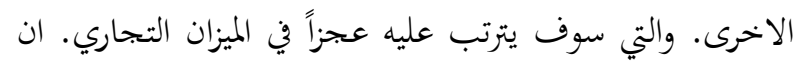
تلافي هذا العجز مناطا بالقدرة على إنتاجه. ثم إن الغذاء لم يعد

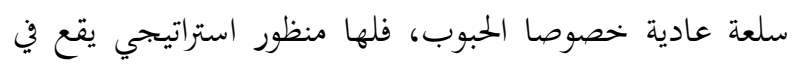
باب الامن الغذائي الذي يعد احد أدوات الحرب أثناء الازمات الاقليمية. لهذه الاسباب بحتمعة فان مهمة إنتاج الغذاء محليا تعتبر موقفاً وطنياً وانسانياً. 2- مساهمة القطاع الزراعي في تكوين الناتج المحلي

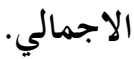
يتكون الناتج المحلي الاجمالي من مجموع مساهمات القطاعات المكونة للنشاط الاقتصادي. وانسجاما مع أهمية القطاع الزراعي المتمثلة بحجم المساحة الجغرافية التي يمتد عليها

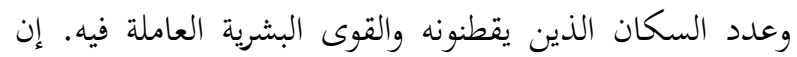
انخفاض نسبة هذه المساهمة تؤدي الى إضعاف مستوى التراكم الرأسمالي الذي يعد ضروريا لعملية التنمية الاقتصادية الشاملة. (فالزراعة اليابانية على سبيل المثال كانت تمول ما نسبته80\% من موازنة الدولة في الستينيات من القرن العشرين من خلال فرض الضرائب على المدخولات والاراضي الزراعية) (4). 3- مساهمثه في رفع مستوى الدخل للسكان .

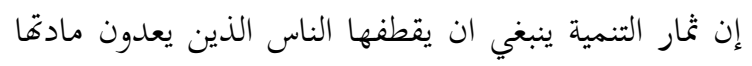

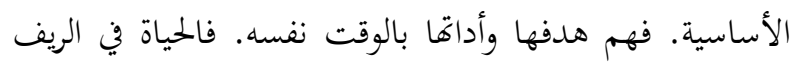
يسودها الفقر المدقع والتخلف بكل أشكاله. فهي مرتعا للامية والخفاض مستوى الخدمات الصحية وارتفاع معدلات وفيات الأطفال، وتسرب اليافعين من مقاعد الدراسة. الامر الذي يجعل وستحل الريف متخلفا ليس فقط وفقا للمقاييس المادية، بل ومتخلفا اكثر وفقا للمقاييس الانسانية او التنمية البشرية. وعليه فان 
من الجدول تبين أن هناك مساحات واسعة صالحة للاستثمار الزراعي وبالامكان الاستفادة من هذه المساحة في

$$
\text { التنمية الزراعية. }
$$

جدول(2-1) ييين نمطاستخدام الاراضي في محافظة الحسكة لعام 2017

\begin{tabular}{|c|c|c|}
\hline \% من مساحة المحافظة & المساحة & نمط الاستخدام \\
\hline 67.2 & 1566008 & أراضي قابلة للزراعة \\
\hline 67.1 & 1561345 & مستثمرة - \\
\hline 0.2 & 4663 & غير مستثمرة- \\
\hline 3.6 & 83501 & ابنية ومرافق عامة \\
\hline 0.9 & 20607 & اتهار وبحيرات \\
\hline 1.8 & 40488 & أراضي صخرية \\
\hline 26.18 & 622755 & مراع ومروج واراضي حراجية \\
\hline
\end{tabular}

المزروعة فعلا. بينما تعتمد النسبة المتبقية والبالغة 30\% على

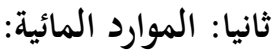

الامطار وتسمى الزراعة البعلية.

ثالثا: الأيدي العاملة الزراعية:

تعد محافظة الحسكة من المحافظات الي تمتاز بارتفاع معدل

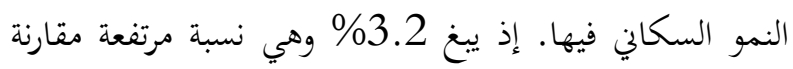

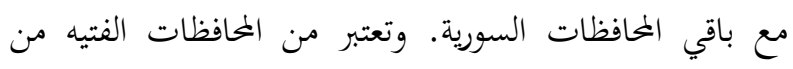
حيث تكوينه السكاني. حيث يمتاز بارتفاع نسبة الفئة الشابة

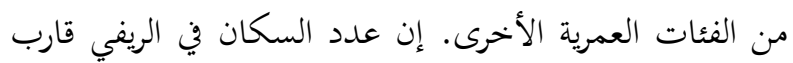
ثلثي سكان المحافظة. (5) حيث تشير اسقاطات السكان لعام 2015الجدول (2-3) إن السكان في المحافظة يبلغ قرابة 1,4مليون نسمة. وان نسبة سكان الريف تبلغ 61,4\%، لان محافظة الحسكة زراعية ومعظم

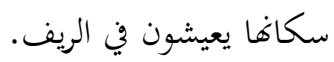

أي مانسبته 67.1\% من المساحة الكلية الى استثمار كامل لماراضي الصالحة للزراعة. 
جدول(2-2) ييين مصادر المياه المتوفرة والقابلة للاستخدام للسنوات 2010-2015

\begin{tabular}{|c|c|c|c|}
\hline مياه جوفية قابلة للسحب & المياه السطحية المسحوبة & المياه السطحية / مليارم3 & السنة السنة \\
\hline 2,1 & 1.5 & 1.8 & 2010 \\
\hline 2,1 & 2.0 & 2.7 & 2011 \\
\hline 2.1 & 2.5 & 3.6 & 2012 \\
\hline 3,1 & 3.3 & 5.1 & 2013 \\
\hline 3,4 & 4.8 & 4.1 & 2014 \\
\hline \multirow[t]{2}{*}{2,1} & 3.5 & 2.8 & 2015 \\
\hline & 2.9 & 3.4 & لمتوسط العاد \\
\hline
\end{tabular}

إن ميزان القوى العاملة يشير إلى أن نسبة القوى العاملة الزراعية إلى قوة العمل الاجمالية تبلغ 54\% كما يتضح من الشكل(1-1 ).

\section{\% الفعاليات الاقتصادية}
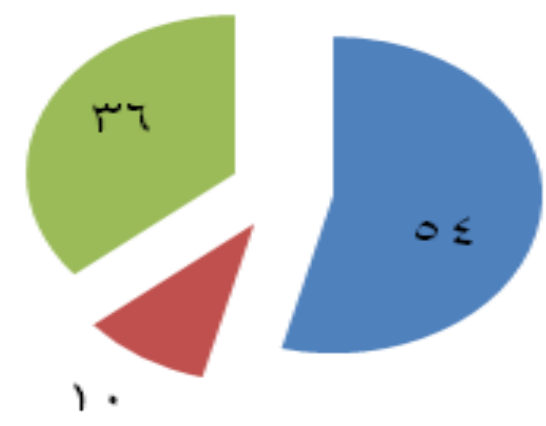

الشكل رقم (1-1 1-: : يبن توزع قوة العمل حسب أوجه النشاط الاقتصادي لعام 2015\%

المصدر :رئاسة بحلس الوزراء، البمموعة الاحصائية السنوية 2015
التطور الكبير في اعدادها فإها ما زالت دون مستوى الحاجة

الحقيقية. حيث يشير معيار نسبة المكائن إل وحدة المساحة الى وجود فجوة كبيرة بين الموجود الفعلي والحاجة الحقيقة. أن مؤشر الجرارات يشير إلى ان كل جرار يخدم 10هكتارا. وهذا يعني وجود عجزا في اعدادها لان المعيار الواقعي لعمل الجرارات في الظروف المتوسطة لا يتعدى 7هكتارا(6)، وكذلك الحال نفسه بالنسبة للحاصدات والمضخات.
رابعا: المكننة الزراعية: تعد المكائن الزراعية من اهم العناصر الضرورية لتطوير القطاع الزراعي لما لها من دور في رفع إنتاجية وحدة المساحة من الاراضي الزراعية ورفع إنتاجية العنصر البشري. إن الواقع العملي يشير إلى الخفاض اعداد هذه القوى الميكانيكية وبالتالي ضعف دورها في تطوير هذا القطاع. كما يبينه الجدول(2-4). يتضح من الجدول اللاحق رقم(2-4) انه على الرغم من 


\begin{tabular}{|c|c|c|c|c|c|c|c|c|}
\hline$\%$ & 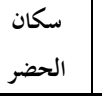 & $\%$ & 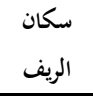 & $\%$ & الاناث & $\%$ & الذ الذكور & المجموع \\
\hline$\% 38,6$ & 590 & $\% 61,4$ & 860 & $\% 42$ & 575 & $\% 58$ & 825 & 1400 \\
\hline \multicolumn{9}{|c|}{ 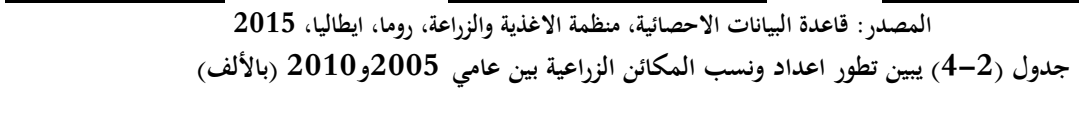 } \\
\hline \multicolumn{2}{|c|}{ نسبة المكائن الى المساحة } & \multicolumn{3}{|c|}{ سبة الزيادة في اعدادها \% } & \multicolumn{2}{|c|}{2016} & 2010 & نوع الماكنة \\
\hline \multicolumn{3}{|c|}{ 1 جرارات لك 10هـ } & \multicolumn{2}{|c|}{86} & \multicolumn{2}{|c|}{9321} & 8019 & الجرارات \\
\hline \multicolumn{3}{|c|}{ 1,1حصادة لكل 10هـ } & \multicolumn{2}{|c|}{75,8} & \multicolumn{2}{|c|}{1876} & 1423 & حصادات دراسات \\
\hline \multicolumn{3}{|c|}{ 18,8مضخات لكل 10 هـ } & \multicolumn{2}{|c|}{82,7} & \multicolumn{2}{|c|}{31987} & 26465 & مضخات \\
\hline
\end{tabular}

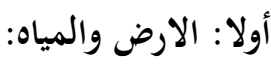

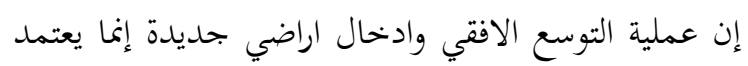

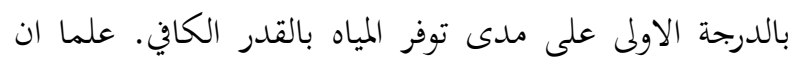
هذه المياه تخضع الى تجاذبات سياسية مع تركيا (دول المنيع) فهي بذلك ستكون تحت رحمة تركيا. وعليه لاغراض التخطيط

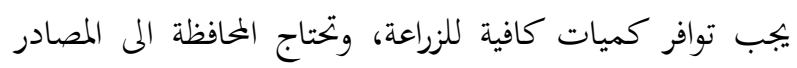

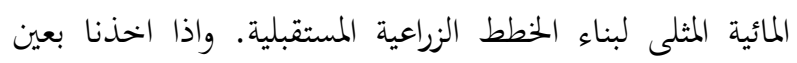

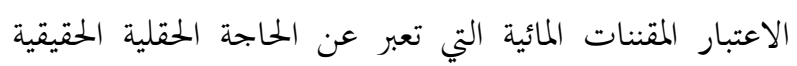
للمياه من دون اسراف وهي متنوعة حسب نوعية الترب الزراعية اذا كانت رملية او طينية وحسب انواع المحاصيل الحقلية اذا لوال

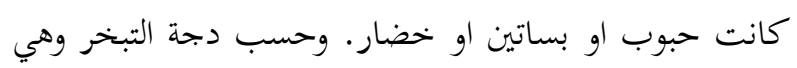

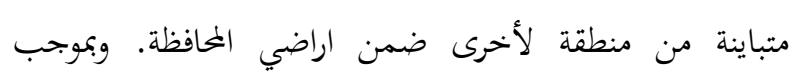
العلاقات بين هذه المتغيرات السابقة يتضح ان المياه بشكلها الحالي من حيث كمياتا او طريقة استخدام الري التقليدي وهي ذات كفاءة قليلة تقدر بحدود 40-50\% قادرة على ارواء

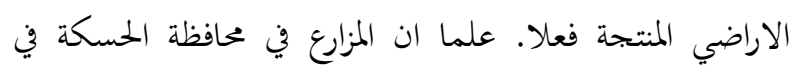

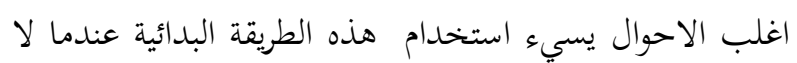

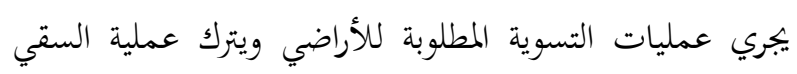
بشكلها العفوي مما يؤدي الى تركز المياه في المناطق المنخفضة

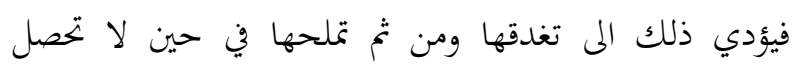
المناطق المرتفعة على كفايتها من المياه. وبذلك تمدر الارض تهرئ
خامسا: الحيازات الزراعية: يعكس نوع الحيازة وحجمها مدى ارتباط الفلاح بأرضه. حيث يترتب على هذه العلاقة العديد من الآثار الاقتصادية والاجتماعية. حيث تعرف الحيازة الزراعية على أها وضع اليد

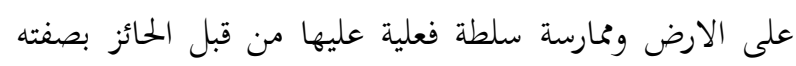

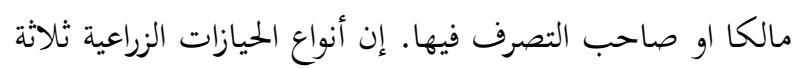

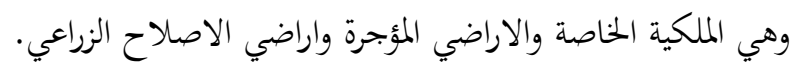
المبحث الثالث: الافاق المستقبلية لخيار التنمية الزراعية

\section{في محافظة الحسكة}

منذ أن عرف الانسان الزراعة، سعى جاهدا لتطويرها، وحاول أيضاً قدر إمكانه قهر عامل الطبيعة المعرقلة لإنتاج الزراعي · فهو استطاع بفضل المكننة الحديثة، من اقامة المدرجات على المنحدرات الجبلية، وزرعها واثبات التربة لمنعها

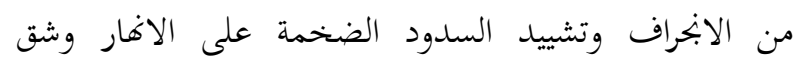
القنوات (7).

وتمتلك محافظة الحسكة الجوانب الايجابية في الاستثمار

$$
\text { الزراعي ومنها: }
$$

1-تنوع بيئاها الزراعية2- توفر اليد العاملة 3-وجود التربة الخصبة

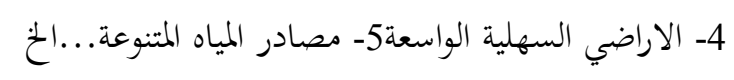


سادسا: اعتماد الزراعة الكثيفة وتبني التخصص في الانتاج

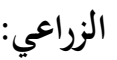

ان التخصص في الانتاج الزراعي يهقق الاستفادة من الظروف البيئة والاقتصادية والاستخدام الامثل للمكائن

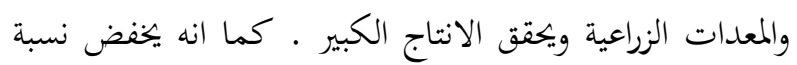

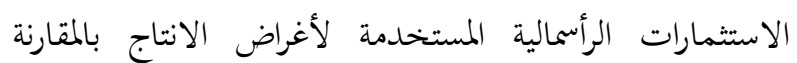

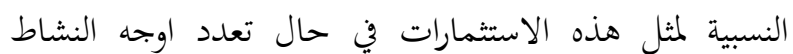
الاقتصادي في المزرعة. كما ان التخصص يلعب دورا في رفع

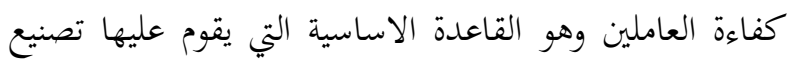

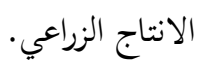
سابعا:تكامل الزراعة مع الصناعة: من المهم ان يسيرا القطاعين الصناعي والزراعي في الاقتصاد الوطني على خطين متوازيين وبصورة تكاملية. ولا بحال للتنمية الصناعية إلا بالتنمية الزراعية ـ خصوصين متورين وبهورة الصناعات التحويلية ذات الصلة الوثيقة بالزراعة. وهنا من الاشارة الى التجربة الصينية التي ركزت على اعطاء الاولوية لتنمية الصناعة بينما احتلت

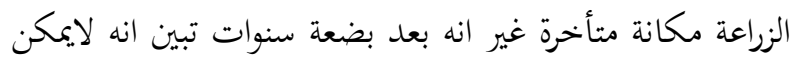

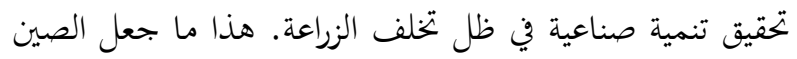
تدخل تغييرات هامة في الاولويات في المدى القصير. بحيث اعطيت الزراعة المكان الاول ثمث الصناعات الاستهلاكية فالصناعات الرأسمالية. (9)

ثامنا: تمويل التنمية الاقتصادية:

تعتبر الزراعة مصدرا مهما لتمويل التنمية الاقتصادية

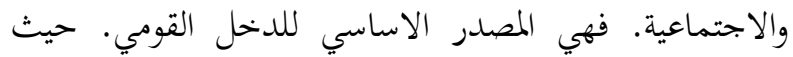
تشير التجربة اليابانية المى ان النمو الاقتصادي الكبير في الانتاج الزراعي هو الذي سمح بتحويل الفائض الاقتصادي المتحقق في

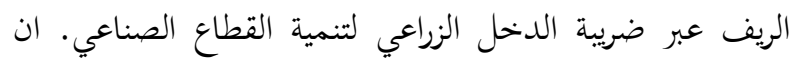

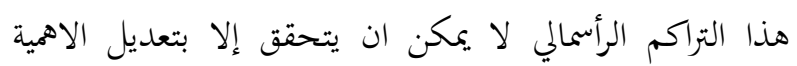

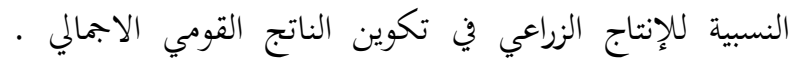
حيث تشير الدراسات الى ان قدرة القطاع الزراعي في المساهمة في تكوين الدخل القومي الاجمالي تصل الى 40\% منه اذا ما توفرت له مستلزمات تطويره واعطي الاهمية التي يستحقها.(10)
والمياه معا ـ واذا اخذنا بعين الاعتبار امكانية استخدام وسائل الري الحديثة وهي الري بالرش والري بالتنقيط وهي ذات كفاءة تقدر بحدود 90\%. سيكون بمقدور المياه الاراضي الزراعية المستثمرة الآن. فضلا عن وجود وسائل اخرى لتنمية الموارد المائية السطحية والجوفية. ثانيا: القوى البشرية: - (مانيه تبين من خلال المعلومات السابقة في البحث، بأن عدد المدانه سكان في منطقة الدراسة وتركيب العمري يتناسب وبشكل كير مع عملية التنمية الزراعية إذا أحسنت استخدامهم. وكل الدلائل تشير إلى خبرة الفلاحين في المنطقة ، لكن المنطقة بحاجة إلى

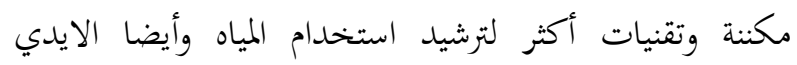
العاملة.

ثالثا: اعادة صياغة العلاقات الانتاجية على نحو افضل:

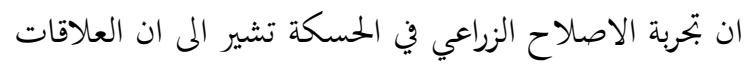
القبلية والاسرية اصبحت هي البديل عن علاقات الانتاج

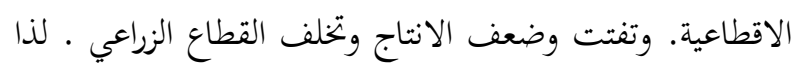

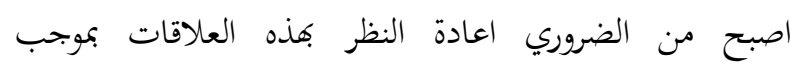
مقاسات المرحلة الراهنة. التي تشير الى ان الدولة قد اختارت

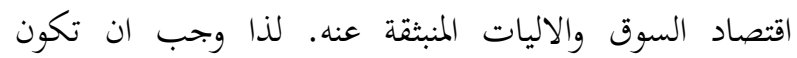
علاقات الانتاج منسجمة معه ايضا. وهي علاقات الانتاج الرأسمالية والعمل على تحويل الحيازات الصغيرة الى حيازات كبرة

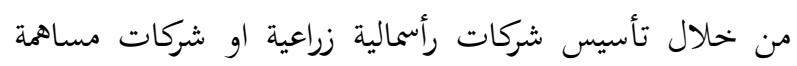

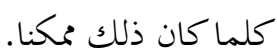

\section{رابعا: توسيع حجم الاستثمارات الزراعية افقيا وعموديا:}

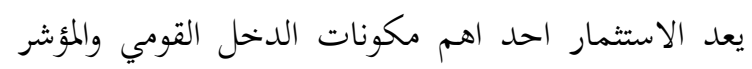

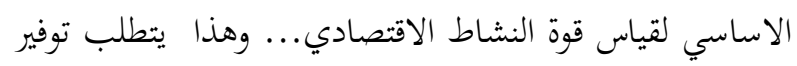

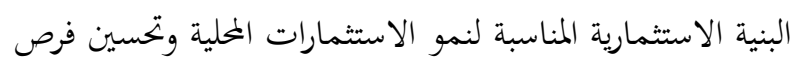

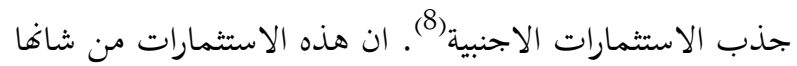
خلق فرص العمل الجديدة وادخال التقنية الحديثة .

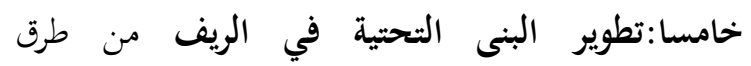
ومواصلات ووسائل اتصال وكهرباء وتنظيم قنوات الري وتطوير السدود وايصال الماء الصالح للشرب. 
3- تشجيع إجراء بحوث زراعية، وتطبيق نتائجها في المجالات

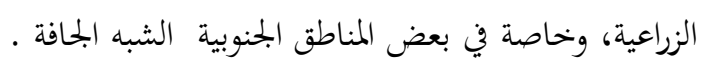
4- ضر ور ة استخدام تقانات الري الحديثة (الري بالرذاذ وبالتنقيط) للحفاظ على الموارد المائية .

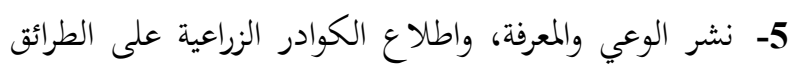

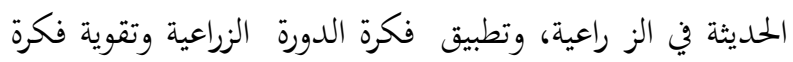

$$
\text { المرشدين الزراعين. }
$$

6- اقامة صناعات غذائية تعتمد على مواد الخام الزراعية المتوفرة

$$
\text { في ار اضي محافظة الحسكة. }
$$

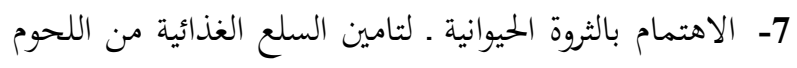
الحمراء والبيض والاسماك واستخدم الاساليب العلمية الحديثة في تربية الحيوان والدواجن والاسماك، والربط بين الانتاج النباتي

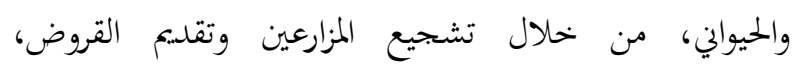

$$
\text { ومستلزمات الثروة الرعوية الاخرى. }
$$

8-8 -8 وعالجة التنمية الزراعية المستدامة كجزء متكامل من التنمية الاقتصادية والاجتماعية الشاملة في المحافظة وفي سورية. وتحقيق المزيد من الترابط بين التنمية الزراعية وباقي الانشطة الاقتصادية.

\section{الهوامش}

(1) رئاسة بحلس الوزراء، البمموعة الاحصائية العامة لعام 2011.

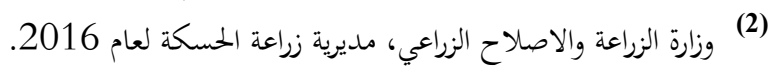

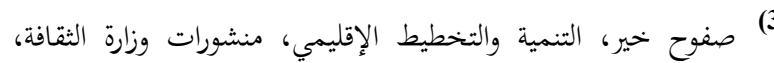

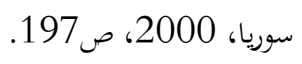

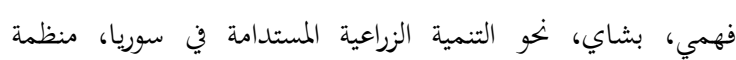

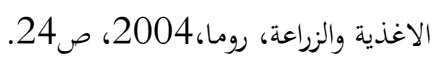

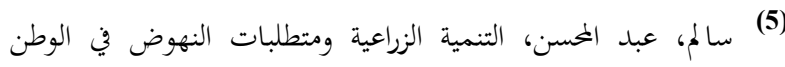

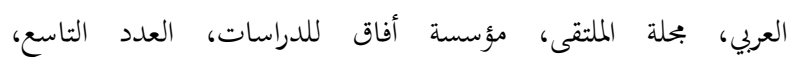

$$
\text { 2008، 20127 }
$$

(6) وزارة الزراعة والاصلاح الزراعي، مديرية زراعة الحسكة، لعام 2017 (7)

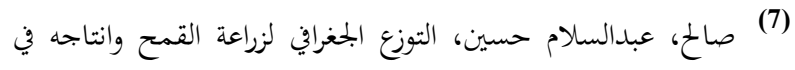
محافظة الحسكة، رسالة الماجستير، جامعة دمشق، 2011.

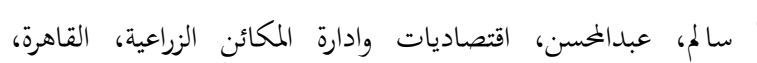
ص196.

\section{الاستنتاجات والتوصيات}

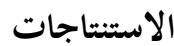

$$
\text { الاستنتاجات التي توصل اليها الباحث هي الآتي: }
$$

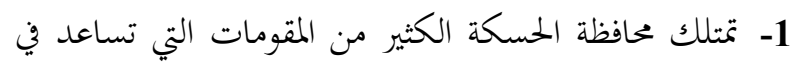
التنمية الزراعية المستدامة كالموارد الارضية والمياه، والتربة، وبالإضافة المى القوى البشرية التي تعمل في القطاع الزراعي.

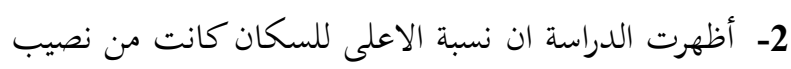
القرى حيث بلغت حوالي 62\% في القرى و38\% في المدينة، لان القطاع الرئيسي في المحافظة هو القطاع الزراعي. 3- إن ميزان القوى العاملة يشير إلى أن نسبة القوى العاملة

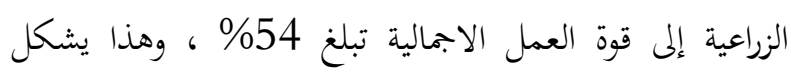
العامل المهم في وضع الخطط التنمية الزراعية المستدامة في اراضي لرئي

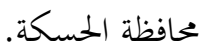
4- تواجه عمليات التنمية الزراعية المستدامة في محافظة الحسكة العديد من التحديات ، منها مناخية ومنها بشرية ، كالسياسة الزراعية وتفتت الحيازات وغيرها. 5- تبينت من خلال الدراسة ان هناك نقص في اعداد الاليات

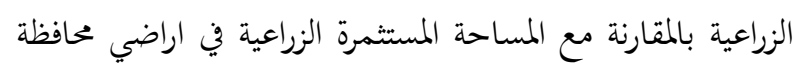

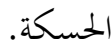
6- تبين من خلال دراسة التنبؤ المستقبلي للمقومات التنمية الزراعية المستدامة في اراضي محافظة الحسكة، أن هذه المؤشرات

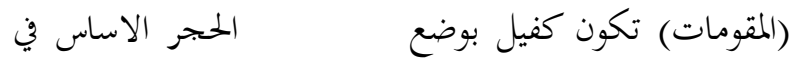
عملية تطوير وتنمية القطاع الزراعي بشكل الامثل.

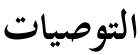

1- العمل على إجراء مسح دقيق ومتكامل للموارد الزراعية في

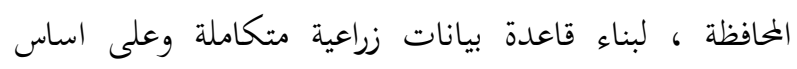
المناطق الادارية لوضع خطط وبرامج تنموية زراعية مستدامة.

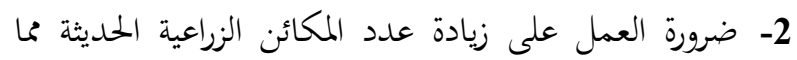
يساعد على زيادة الانتاجية والتقليل من الحاجة الى اليد العاملة وتخفيض تكاليف العملية الانتاجية. 


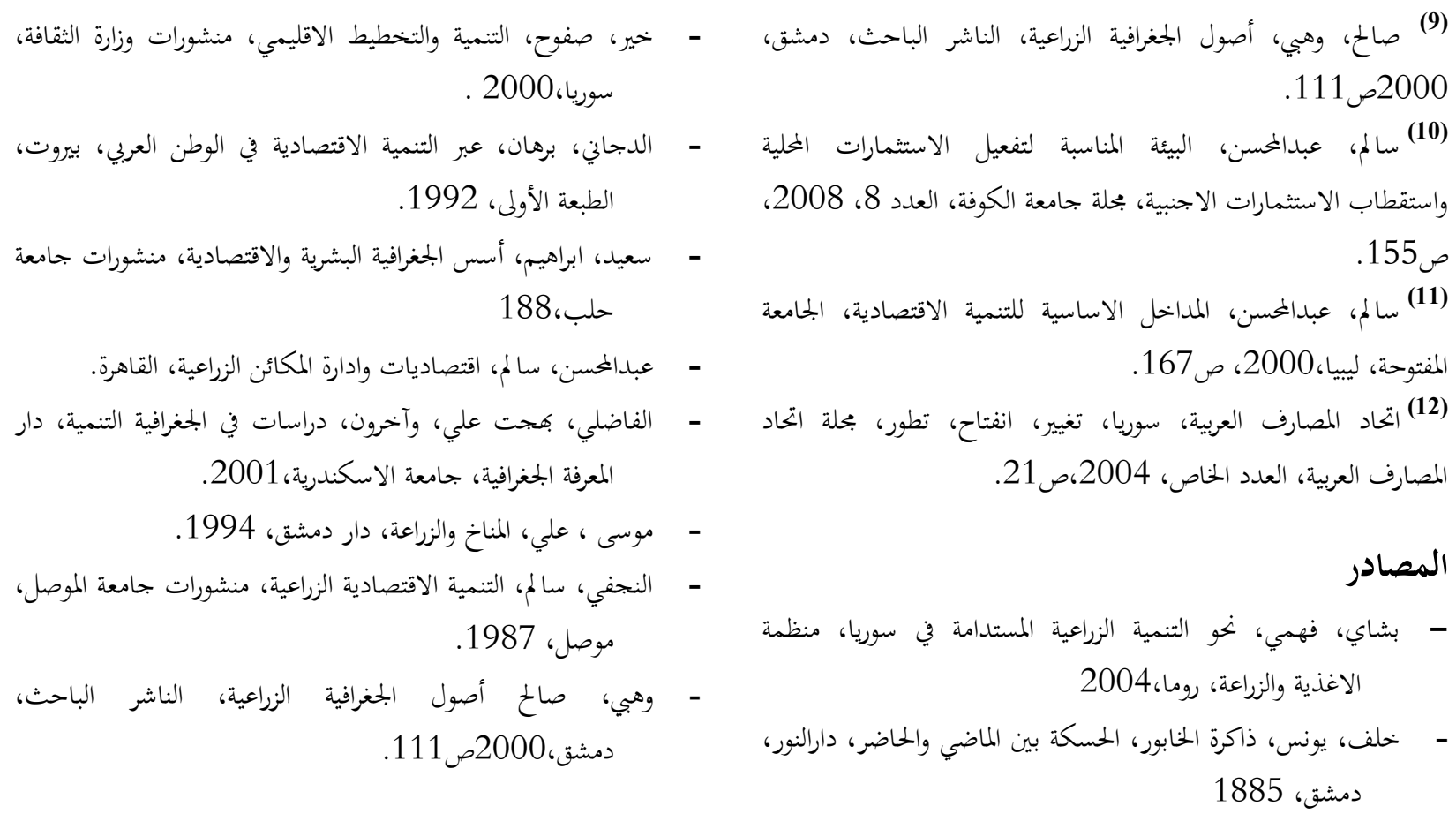

\title{
SUSTAINABLE AGRICULTURAL DEVELOPMENT IN AL HASAKAH GOVERNORATE (GEOGRAPHICAL STUDY)
}

\begin{abstract}
The agricultural development acquired it is significance from the importance and vividly of the agricultural sector in which it works and moves. The agricultural sector is considered to be the main source for the capitation and liberate the man power at the same time the agriculture sector is the cardinal resource to support the local industries with the basic raw material and a wide market to process it is goods. Therefore the agricultural to development is considered to be the necessary first steps to accomplish the comprehensive development.
\end{abstract}

